\title{
Model Kuantitatif Audit Pendokumentasian terhadap Kelengkapan Rekam Medis
}

\author{
Lily Widjaja ${ }^{1}$, Siswati ${ }^{2}$ \\ Universitas Esa Unggul, Jakarta, Indonesia \\ Jl.Pegangsaan Indah Barat II/12, Pegangsaan Dua, Kelapa Gading, Jakarta Utara, 12450 \\ lily.widjaja@esaunggul.ac.id
}

\begin{abstract}
Appropriate and structured Medical Records documentation audit is required in measuring the achievement of Medical Record Completeness (MR) indicators in hospitals. Based on observations of the implementation of MR documentation audit in a hospital, it was found that the measured MR components varied greatly, and did not know the quantitative model of MR documentation audit. This study aims to determine the effect of Quantitative Audit Model Documentation on Completeness of MR. The hypothesis of this study is the influence of Quantitative Audit Model Documentation on Completeness of MR. This type of research is a quasi-experimental using the pretest and Posttest design, Non-Equivalent Control Group Design. The measurement of the completeness of medical records was carried out by students using conventional models and quantitative models of RM documentation audit. The population is 30 students with saturated samples. The dependent variable is MR Completeness and the independent variable is the Audit Model MR Documentation. The research instrument is a checklist. Research analysis using dependent T-test. The results of this study there are significant differences in the average value of the completeness of all components before and after the application of a quantitative audit documentation model reflects that the implementation of this model is better than the conventional model. This Quantitative Model can track each component of the medical record being audited, allowing correction of parts that can still be equipped, structured so that they can measure up to this RM completeness subcomponent.
\end{abstract}

Keywords: Medical record, documentation audit, quantitative model

\section{PENDAHULUAN}

Akreditasi merupakan pengakuan publik oleh badan akreditasi kesehatan nasional untuk pencapaian standar akreditasi oleh organisasi kesehatan, ditunjukkan melalui sebuah penilaian dari badan eksternal yang independen dari tingkat organisasi kinerja yang terkait dengan standar. Tujuan akreditasi adalah peningkatan mutu pelayanan rumah sakit yang bukan semata-mata sertifikat kelulusan. Dalam upaya peningkatan mutu pelayanan Rumah Sakit wajib dilakukan akreditasi secara berkala minimal 3 (tiga) tahun sekali. (KARS, 2017).

Berdasarkan Profil Rumah sakit (RS) di Indonesia tahun 2015, jumlah rumah sakit umum sebanyak 2488 buah dan RS Khusus sebanyak 539 buah. (Kemenkes, 2016). Sebanyak 849 diantaranya telah terakreditasi dengan menggunakan standar akreditasi 2012. Bab 1 standar akreditasi 2012 "Kelompok Standar Manajemen Rumah Sakit, terkait Peningkatan Mutu Pelayanan Dan Keselamatan Pasien (PMKP)". Pimpinan rumah sakit perlu menetapkan indikator kunci untuk memonitor struktur, proses dan hasil (outcome) dari rencana PMKP yang dilakukan berdasarkan tersedianya data. Penggunaan data secara efektif dapat dilakukan berdasarkan evidence-based praktek klinik dan evidence-based praktek manajemen (Toto, 2011). Satu diantara sebelas (11) indikator yang terkait dengan area klinik yang terkait kelengkapan data pasien adalah indikator: Ketersediaan, isi dan penggunaan Rekam Medis (RM). Untuk itu perlu meningkatkan mutu pendokumentasian RM dengan melakukan audit terhadap pendokumentasian dokter dan tenaga kesehatan lainnya.

Selain itu RM penting untuk kelanjutan pelayanan oleh pemberi pelayanan terutama dokter dan perawat, juga sebagai bukti hukum bila digunakan pada kasus pengaduan/ tuntutan dari pasien/ keluarganya yang tidak puas terhadap layanan, pada saat ada tuntutan bila tidak lengkap maka tidak bisa digunakan sebagai bukti bahwa pemberi pelayanan telah dilakukan sesuai dengan Panduan Praktik Klinis untuk dasar pembayaran. RM saat ini digunakan sebagai dasar pembayaran yang dilaksanakan oleh BPJS saat 
ini. Bila RS akan menagih biaya dari pasien BPJS maka perlu bukti minimal ringkasan penyakit yang lengkap dan bukti pelayanan/tindakan yang dilakukan. Apalagi bila bukti yang seharusnya ada tidak ditemui dalam RM pasien tersebut, sehingga RS mengalami kerugian. Dengan perlunya rekam medis yang lengkap, maka audit pendokumentasiannya wajib dilakukan.

Berdasarkan Undang-undang Praktik Kedokteran (2004) pasal 46 ayat 1 dikatakan bahwa "Setiap dokter atau dokter gigi dalam menjalankan praktik kedokteran wajib membuat rekam medis". Pada Pasal 79 ayat 2 menyatakan "Bila dokter atau dokter gigi yang dengan sengaja tidak membuat Rekam medis dapat dipidana dengan pidana kurungan paling lama 1 (satu) tahun atau denda paling banyak Rp50.000.000,00 (lima puluh juta rupiah).

Model Audit pendokumentasian yang tepat belum dilakukan sepenuhnya oleh rumah sakit walaupun diwajibkan untuk mengukur indikator kelengkapan RM. Pelaksanaan audit pendokumentasian RM dilakukan oleh Praktisi Manajemen Informasi Kesehatan (PMIK) tetapi belum dapat mengevaluasi dan merekomendasi perbaikan apa yang harus dilakukan demi terciptanya data yang dapat dijadikan evidence base. Dari hasil audit 3 tahun terakhir tidak ada peningkatan kualitas pendokumentasian RM. Dampak dari model Audit yang tidak terstruktur akan sulit untuk meningkatkan kualitas pendokumentasian RM.

Untuk tingkatan analisis kuantitatif yang lebih mahir praktisi jangan hanya berfokus pada penganalisian kelengkapan data social pasien dan lembaran medis belaka, juga harus mengintegrasikan kegiatan yang berdampak hukum dan atingingive dengan pelayanan kesehatan yang dititik beratkan pada kelengkapan data ating, bukti rekaman yang ada, tanda bukti keabsahan dan tata cara mencatat (Hatta, 2008). Oleh karena itu PMIK di RS harus mempunyai kompetensi terkait memahami jenis formulir yang digunakan, orang yang berhak mengisi RM dan yang melegalisasi penulisan agar hasil audit yang dilakukan maksimal dan RM dapat digunakan untuk berbagai keperluan.

Penelitian Ripto Sayono (2011) dalam penelitian "Tinjauan Kelengkapan Rekam Medis Rawat Inap Penyakit Dalam Di RSUD Pasar Rebo", disimpulkan terdapat $50(100 \%)$ lengkap dicantumkan identifikasi pasien, $48(96 \%)$ terisi kelengkapan laporan yang diperlukan, $25(50 \%)$ terisi autentikasi penulis dan $13.6(27.3 \%)$ terisi catatan yang baik.
Ayu Lima (2012) dalam Tinjauan Kelengkapan Rekam Medis Rawat Inap Pada Pembuatan Resume Medis Di Rumah Sakit Siaga Raya Jakarta"; rata-rata persentase kelengkapan rekam medis rawat inap pada pembuatan resume medis di bulan Februari 2012 adalah $42 \%$. Kelengkapan rekam medis rawat inap pada pembuatan resume medis di Rumah Sakit Siaga Raya masih kurang baik, karena masih banyak rekam medis rawat inap yang tidak dibuatkannya resume medis oleh dokter. Ketidak lengkapannya rekam medis rawat inap pada pembuatan resume karena kesibukan dokter dan kurangnya pengetahuan tentang pentingnya resume medis.

Pada perbandingan penggunaaan model pembelajaran juga dapat dilihat dari penelitian Eka Trisianawati et.al.(2015) dalam penelitian "Pengaruh Model Pembelajaran Kooperatif Tipe Jigsaw Terhadap Hasil Belajar Siswa Pada Materi Vektor Di Kelas X SMA Negeri 1 Sanggau Ledo" menyimpulkan bahwa Penerapan model pembelajaran Kooperatif Tipe Jigsaw memberikan pengaruh yang signifikan terhadap hasil belajar siswa. Terdapat perbedaan hasil belajar pada materi ating yang diajarkan dengan model pembelajaran Kooperatif Tipe Jigsaw dan yang diajarkan dengan model pembelajaran diskusiceramah pada siswa kelas

Sani (2016) dalam penelitian "Perbedaan Hasil Belajar Siswa Menggunakan Model Pembelajaran Latihan Inkuiri Dengan Pembelajaran Konvensional Pada Mata Pelajaran Fisika" disimpulkan bahwa ada perbedaan yang signifikan hasil belajar siswa dalam mata pelajaran fisika yang diajar model inkuiri dengan pembelajaran konvensional.

Berdasarkan survei awal yang dilakukan di RS Patria IKKT terdapat permasalahan belum terlaksananya pendokumentasi RM yang lengkap. Penggunaan model audit yang konvensional kurang mencerminkan kelengkapan yang dapat dikoreksi. Hal ini memberikan efek kurangnya perhatian para dokter dan tenaga kesehatan yang mengisi RM untuk melakukan peningkatan kelengkapan dalam pendokumentasian. Dan akan berdampak pada ketidaklengkapan pendokumentasian yang berkesinambungan.

Dalam mengatasi permasalahan tersebut maka hendaknya rumah sakit memilih dan menerapkan model audit pendokumentasian yang tepat, memberikan penyajian hasil yang mudah diterima dan memberi dampak, sehingga dapat memberi stimulus bagi para dokter dan tenaga kesehatan untuk melakukan pendokumentasian yang 
lengkap dan berkualitas. Dalam hal ini adalah audit pendokumentasian rekam medis dengan menggunakan model kuantitatif sebagai pengganti model yang masih konvensional. Berdasarkan latar belakang tersebut perlu dilakukan penelitian dengan judul "Pengaruh Model Kuantitatif Audit Pendokumentasian Rekam Medis Terhadap Kelengkapan Rekam Medis”.

\section{METODE PENELITIAN}

Jenis penelitian ini adalah eksperimen semu (quasi experiment) dengan menggunakan rancangan PretestPosttest, Non-Equivalent Control Group Design. Pada penelitian ini akan dilakukan pengukuran kelengkapan rekam medis pada penerapan model konvensional audit pendokumentasian rekam medis dan model kuantitatif audit pendokumentasian rekam medis.

Populasi dalam penelitian ini adalah mahasiswa D3-Rekam Medis dan Informasi Kesehatan, Fakultas Ilmu-ilmu Kesehatan, Universitas Esa Unggul semester 3 sebanyak 30 orang. Sampel yang diambil adalah sampel jenuh. Instrumen penelitian ini adalah check list (daftar tilik dan rekapitulasi) dan pedoman wawancara. Cara pengumpulan data dengan melakukan pengukuran kelengkapan pengisian rekam medis dengan model konvensional audit pendokumentasian rekam medis dan model kuantitatif audit pendokumentasian rekam medis.

Teknik pengumpulan data dengan Editing kegiatan koreksi terhadap ketidaklengkapan atau kesalahan data penelitian dengan tujuan untuk segera melakukan perbaikan, kemudian Coding merupakan kegiatan pemberian kode pada lembar observasi/check list bertujuan untuk memudahkan pengolahan data, Scoring kegiatan pemberian skor pada variabel kelengkapan rekam medis dan Entry data kegiatan memasukkan data penelitian ke komputer untuk memudahkan dalam pengolahan data penelitian.

\section{HASIL DAN PEMBAHASAN}

Analisis Univariat

a. Rata-rata kelengkapan rekam medis model konvensional dan model kuantitatif audit pendokumentasian

Pada model kuantitatif tiap komponen mempunyai beberapa subkomponen.
Subkomponen dari masing-masing komponen model kuantitatif ini dapat diperinci sebagai berikut dan hasilnya dibandingkan dengan model konvensional:

Tabel 1

Hasil Audit Komponen 1: Kelengkapan Identifikasi pasien dengan menggunakan Model Konvensional dan Kuantitatif Audit Pendokumentasian Rekam Medis

\begin{tabular}{|c|c|c|c|}
\hline \multirow[b]{2}{*}{ No } & \multirow{2}{*}{$\begin{array}{c}\text { Subkomponen } \\
\text { Analisis }\end{array}$} & \multicolumn{2}{|c|}{ Kelengkapan } \\
\hline & & $\begin{array}{c}\text { Model } \\
\text { Konvensional }\end{array}$ & $\begin{array}{c}\text { Model } \\
\text { Kuantitatif }\end{array}$ \\
\hline \multicolumn{4}{|c|}{ Kelengkapan Identifikasi Pasien } \\
\hline 1. & Nama & $100.00 \%$ & $100.0 \%$ \\
\hline 2. & $\begin{array}{l}\text { No. Rekam } \\
\text { Medis }\end{array}$ & $100.00 \%$ & $100.0 \%$ \\
\hline 3. & Tanggal Lahir & $83.33 \%$ & $99.3 \%$ \\
\hline 4. & Jenis Kelamin & $86.67 \%$ & $97.3 \%$ \\
\hline & Average & $92.5 \%$ & $99.2 \%$ \\
\hline
\end{tabular}

Dari tabel di atas komponen kelengkapan identifikasi pasien dapat diperinci bahwa ke empat subkomponennya sangat lengkap dari semua subkomponen $=99.2 \%(97.3 \%-100 \%)$. Sedangkan model konvensional rata-rata kelengkapannya $=92 \%(83.33 \%-100 \%)$

Tabel 2

Hasil Audi Komponen 2: Kelengkapan Laporan Penting dengan menggunakan Model Konvensional dan Kuantitatif Audit Pendokumentasian Rekam Medis.

\begin{tabular}{|c|c|c|c|}
\hline \multirow[b]{2}{*}{ No } & \multirow[b]{2}{*}{$\begin{array}{c}\text { Subkomponen } \\
\text { Analisis }\end{array}$} & \multicolumn{2}{|c|}{ Kelengkapan } \\
\hline & & $\begin{array}{c}\text { Model } \\
\text { Konvensional }\end{array}$ & $\begin{array}{c}\text { Model } \\
\text { Kuantitatif }\end{array}$ \\
\hline \multicolumn{4}{|c|}{ Laporan yang Penting } \\
\hline 1. & $\begin{array}{l}\text { Pengkajian } \\
\text { awal }\end{array}$ & $90.00 \%$ & $100.0 \%$ \\
\hline 2. & $\begin{array}{l}\text { Cat. } \\
\text { Perkembangan }\end{array}$ & $89.33 \%$ & $97.3 \%$ \\
\hline & $\begin{array}{l}\text { Informed } \\
\text { Consent }\end{array}$ & $85.33 \%$ & $98.0 \%$ \\
\hline & $\begin{array}{l}\text { Bukti } \\
\text { Pengobatan \& } \\
\text { Perawatan }\end{array}$ & $91.33 \%$ & $78.0 \%$ \\
\hline 5. & $\begin{array}{l}\text { Cat. Saat } \\
\text { pulang }\end{array}$ & $97.33 \%$ & $98.7 \%$ \\
\hline & Average & $90.67 \%$ & $94 \%$ \\
\hline
\end{tabular}


Lily Widjaja dan Siswati. Model Kuantitatif Audit Pendokumentasian terhadap Kelengkapan Rekam Medis

Dari tabel di atas dari komponen ke 2, kelengkapan laporan penting, dapat diperinci bahwa ada lima subkomponennya dan rata-rata kelengkapan $=94 \%(78 \%-100 \%)$. Dapat diketahui bahwa catatan pengkajian awal, catatan perkembangan dan informed consent lebih lengkap pada model kuantitatif sedangkan Bukti pengobatan \& perawatan serta catatan saat pulang lebih lengkap di banding model konvensional.

Bila dibandingkan dengan hasil rata-rata kelengkapan RM model kuantitatif lebih tinggi kelengkapannya = $84 \%$ dibanding model konvensional $=90.67 \%$

Tabel 3

Hasil Audi Komponen 3:Kelengkapan Autentikasi Penulis dengan menggunakan Model Konvensional dan Kuantitatif Audit Pendokumentasian Rekam Medis

\begin{tabular}{|c|c|c|c|}
\hline \multirow[b]{2}{*}{ No } & \multirow{2}{*}{$\begin{array}{c}\text { Subkomponen } \\
\text { Analisis }\end{array}$} & \multicolumn{2}{|c|}{ Kelengkapan } \\
\hline & & $\begin{array}{c}\text { Model } \\
\text { Konvensional }\end{array}$ & $\begin{array}{c}\text { Model } \\
\text { Kuantitatif }\end{array}$ \\
\hline \multicolumn{4}{|c|}{ Kelengkapan Autentikasi Penulis } \\
\hline 1. & $\begin{array}{l}\text { Nama Dokter } \\
\text { Lengkap }\end{array}$ & $60.67 \%$ & $78.7 \%$ \\
\hline 2. & Tanda tangan & $67.33 \%$ & $90.0 \%$ \\
\hline 3. & Nama Perawat & $68.00 \%$ & $86.0 \%$ \\
\hline 4. & $\begin{array}{l}\text { Tanda tangan } \\
\text { Perawat }\end{array}$ & $83.33 \%$ & $88.0 \%$ \\
\hline & Average & $69.83 \%$ & $85.7 \%$ \\
\hline
\end{tabular}

Dari tabel di atas komponen ke 3, kelengkapan Autentikasi penulis (dokter dan perawat), dapat diperinci bahwa ada empat (4) subkomponennya dan rata-rata kelengkapan model kuantitatif = 85.7\%. (78.7\%-90\%) secara signifikan jauh lebih tinggi atinging kelengkapan pada model konvensional $=69.83 \%(60.67 \%-83.33 \%)$

Tabel 4

Hasil Audit Komponen 4: Teknik Pencatatan yang baik dengan menggunakan Model Konvensional dan Kuantitatif Audit Pendokumentasian Rekam Medis

\begin{tabular}{|c|c|c|c|}
\hline \multirow[b]{2}{*}{ No } & \multirow{2}{*}{$\begin{array}{c}\text { Subkomponen } \\
\text { Analisis }\end{array}$} & \multicolumn{2}{|c|}{ Kelengkapan } \\
\hline & & $\begin{array}{c}\text { Model } \\
\text { Konvensional }\end{array}$ & $\begin{array}{c}\text { Model } \\
\text { Kuantitatif }\end{array}$ \\
\hline \multicolumn{4}{|c|}{ Kelengkapan Autentikasi Penulis } \\
\hline 1. & $\begin{array}{l}\text { Coretan Tidak } \\
\text { ada }\end{array}$ & $84.67 \%$ & $72.0 \%$ \\
\hline
\end{tabular}

\begin{tabular}{llcc}
\hline 2 & $\begin{array}{l}\text { Tipp-ex tidak } \\
\text { digunakan }\end{array}$ & $94.00 \%$ & $94.7 \%$ \\
\hline 3 & $\begin{array}{l}\text { Bagian yang } \\
\text { kosong tidak } \\
\text { ada }\end{array}$ & $23.33 \%$ & $74.7 \%$ \\
\hline & Average model & $67.33 \%$ & $80.4 \%$ \\
\hline
\end{tabular}

Dari tabel di atas terlihat komponen ke 4, teknik pencatatan yang baik, dapat diperinci bahwa ada tiga (3) subkomponennya dan rata-rata pencatatan yang baik $=80.4 \%(74.7 \%-94.7 \%)$. Secara signifikan jauh lebih tinggi atinging pada model konvensional dengan rata-rata $=67.3 \%$ $(23.33 \%-94 \%)$

b. Kelengkapan rekam medis sebelum menerapkan model kuantitatif audit pendokumentasian

Tabel 5

Kelengkapan Rekam Medis Sebelum Penerapan Model Kuantitatif Audit Pendokumentasian

\begin{tabular}{|c|c|c|c|c|c|c|c|}
\hline No & $\begin{array}{c}\text { Review } \\
\text { Keleng- } \\
\text { kapan }\end{array}$ & $\mathrm{N}$ & Mean & SD & $\begin{array}{l}\text { Jum- } \\
\text { lah }\end{array}$ & $\%$ & $\begin{array}{l}\text { Kat- } \\
\text { egori }\end{array}$ \\
\hline 1 & $\begin{array}{l}\text { Identitas } \\
\text { Pasien }\end{array}$ & 150 & 3,70 & 0,58 & 555 & 92,5 & Baik \\
\hline 2 & $\begin{array}{l}\text { Laporan } \\
\text { Penting }\end{array}$ & 150 & 4,53 & 0,77 & 680 & 90,67 & Baik \\
\hline 3 & $\begin{array}{l}\text { Auten- } \\
\text { tifikasi } \\
\text { penulis }\end{array}$ & 150 & 2,80 & 1,05 & 420 & 70 & $\begin{array}{l}\mathrm{Cu}- \\
\text { kup }\end{array}$ \\
\hline 4 & $\begin{array}{l}\text { Tenik } \\
\text { pen- } \\
\text { catatan } \\
\text { yang } \\
\text { baik }\end{array}$ & 150 & 2,02 & 0,607 & 303 & 67,3 & $\begin{array}{l}\mathrm{Cu}- \\
\text { kup }\end{array}$ \\
\hline & $\begin{array}{l}\text { Rata- } \\
\text { rata } \\
\text { keleng- } \\
\text { kapan }\end{array}$ & & & & & 79.98 & \\
\hline
\end{tabular}

Sumber: Hasil Pengolahan SPSS versi 22.00, 2018

Berdasarkan tabel di atas dapat diketahui bahwa kelengkapan rekam medis sebelum penerapan model kuantitatif; Mean $\pm \mathrm{SD}$; Identitas pasien $(3,70 \pm 0,58)=92,5 \%$, Laporan penting $(4,53$ $\pm 0,77)=90,67 \%$, Autentifikasi $(2.80 \pm 1.05)$ $=70 \%$, pencatatan yang baik $(2,02 \pm 0,607)$ $=67,3 \%$. Pencapaian kelengkapan pengisian tertinggi pada identitas pasien dan terendah pada teknik pencatatan yang baik. Rata-rata kelengkapan semua komponen $=79.98 \%$ 
c. Kelengkapan rekam medis sesudah menerapkan model kuantitatif audit pendokumentasian

Tabel 6

Kelengkapan Rekam Medis Sesudah Penerapan Model Kuantitatif Audit Pendokumentasian

\begin{tabular}{|c|c|c|c|c|c|c|c|}
\hline No & $\begin{array}{c}\text { Review } \\
\text { Keleng- } \\
\text { kapan }\end{array}$ & $\mathrm{N}$ & Mean & SD & $\begin{array}{l}\text { Jum- } \\
\text { lah }\end{array}$ & $\%$ & $\begin{array}{l}\text { Kat- } \\
\text { egori }\end{array}$ \\
\hline 1 & $\begin{array}{l}\text { Identitas } \\
\text { Pasien }\end{array}$ & 150 & 3,97 & 0,21 & 595 & 99,2 & Baik \\
\hline 2 & $\begin{array}{l}\text { Laporan } \\
\text { Penting }\end{array}$ & 150 & 4,69 & 0,50 & 704 & 94,0 & Baik \\
\hline 3 & $\begin{array}{l}\text { Auten- } \\
\text { tifikasi } \\
\text { penulis }\end{array}$ & 150 & 3,43 & 0,96 & 514 & 85,6 & Baik \\
\hline 4 & $\begin{array}{l}\text { Tenik } \\
\text { pen- } \\
\text { catatan } \\
\text { yang } \\
\text { baik }\end{array}$ & 150 & 2,41 & 0,66 & 362 & 80,4 & Baik \\
\hline & $\begin{array}{l}\text { Rata- } \\
\text { rata } \\
\text { keleng- } \\
\text { kapan }\end{array}$ & & & & & 89,8 & \\
\hline
\end{tabular}

Sumber: Hasil Pengolahan SPSS versi 22.00, 2018

Berdasarkan tabel di atas dapat diketahui bahwa kelengkapan rekam medis sesudah penerapan model kuantitatif; Mean \pm SD ; Identitas pasien $(3,97 \pm 0,21)$, Laporan penting $(4,69 \pm 0,50)$, Autentifikasi $(3,43 \pm 0,96)$ pencatatan yang baik $(2,41 \pm 0,66)$. Kelengkapan pengisian rekam medis pada katagori baik pada semua komponen kelengkapan. Rata-rata kelengkapan semua komponen $=89.8 \%$.

Undang-undang praktik kedokteran (2004) pasal 46 ayat 1 dikatakan bahwa "Setiap dokter atau dokter gigi dalam menjalankan praktik kedokteran wajib membuat rekam medis" . Pada Pasal 79 ayat 2 menyatakan "Bila dokter atau dokter gigi yang dengan sengaja tidak membuat Rekam medis dapat dipidana dengan pidana kurungan paling lama 1 (satu) tahun atau denda paling banyak Rp50.000.000,00 (lima puluh juta rupiah). Berdasarkan Permenkes 269, (2008) dikatakan bahwa Rekam Medis harus dibuat secara tertulis, lengkap dan jelas. Hal ini dilakukan baik secara manual maupun elektronik.
Kelengkapan rekam medis dengan menerapkan model konvensional audit pendokumentasian (sebelum menerapkan model kuantitatif audit pendokumentasian) berdasarkan Tabel 5 dapat diketahui bahwa Rata-rata kelengkapan semua komponen $=79.98 \%$. Pencapaian kelengkapan pengisian identitas pasien dan laporan yang penting masuk dalam kategori "baik" sedangkan komponen Autentikasi penulis dan Teknik pencatatan yang baik masih dalam kategori "cukup".

Kelengkapan rekam medis dengan menerapkan kuantitatif audit pendokumentasian, berdasarkan Tabel 6 dapat diketahui bahwa kelengkapan rekam medis sesudah penerapan model kuantitatif rata-rata kelengkapan semua komponen $=89.8 \%$. Pencapaian kelengkapan pengisian rekam medis pada katagori "baik" untuk semua komponen.

\section{Analisis Bivariat}

Tabel 7

Hasil Uji Hipotesis

\begin{tabular}{|c|c|c|c|c|c|}
\hline No & $\begin{array}{c}\text { Review } \\
\text { Keleng- } \\
\text { kapan }\end{array}$ & Mean & SD & $\mathrm{p}$ & $\begin{array}{c}\text { Keputusar } \\
\text { Ho }\end{array}$ \\
\hline 1 & $\begin{array}{l}\text { Identitas } \\
\text { Pasien } \\
\text { Sebelum_- } \\
\text { Sesudah_ }\end{array}$ & $-0,267$ & 0,598 & 0,000 & Ditolak \\
\hline 2 & $\begin{array}{l}\text { Laporan } \\
\text { Penting } \\
\text { Sebelum_- } \\
\text { Sesudah }\end{array}$ & $-0,160$ & 0,956 & 0,042 & Ditolak \\
\hline 3 & $\begin{array}{l}\text { Autentifika- } \\
\text { si Sebelum } \\
\text { Sesudah }\end{array}$ & $-0,627$ & 1,468 & 0,000 & Ditolak \\
\hline 4 & $\begin{array}{l}\text { Pencatatan } \\
\text { yag baik } \\
\text { Sebelum_- } \\
\text { Sesudah }\end{array}$ & $-0,393$ & 0,889 & 0,000 & Ditolak \\
\hline
\end{tabular}

Tabel 7 menunjukkan bahwa nilai mean kelengkapan identitas pasien sebelum dan sesudah penerapan model kuantitatif adalah -0,267 (3,70-3,97). Kelengkapan sesudah lebih lengkap dibanding kelengkapan sebelum penerapan model kuantitatif. Dan selisih nilai mean tertinggi terdapat pada kelengkapan autentifikasi $=-0,627(2,80-3,43)$. 
Kelengkapan autentifikasi sesudah lebih lengkap dibanding sebelum penerapan model kuantitatif.

Nilai p pada semua variabel kelengkapan rekam medis adalah $<0.05$ sehingga $\mathrm{H} 0$ ditolak. Hal ini berarti:

1) Ada perbedaan yang signifikan nilai rata - rata kelengkapan identitas pasien sebelum dan sesudah penerapan model kuantitatif audit pendokumentasian pada nilai $\mathrm{p}=0.000$

2) Ada perbedaan yang signifikan nilai rata - rata kelengkapan laporan penting sebelum dan sesudah penerapan model kuantitatif audit pendokumentasian pada nilai $\mathrm{p}=0.042$

3) Ada perbedaan yang signifikan nilai rata rata kelengkapan autentifikasi sebelum dan sesudah penerapan model kuantitatif audit pendokumentasian pada nilai $\mathrm{p}=0.000$

4) Ada perbedaan yang signifikan nilai rata rata kelengkapan pencatatan sebelum dan sesudah penerapan model kuantitatif audit pendokumentasian pada nilai $\mathrm{p}=0.000$

Nilai p pada semua variabel kelengkapan rekam medis adalah $<0.05$ sehingga $\mathrm{H} 0$ ditolak. Hal ini berarti ada perbedaan yang signifikan nilai rata-rata semua komponen model audit kuantitatif berupa kelengkapan identitas pasien, laporan yang penting, autentifikasi penulis dan teknik pencatatan yang baik sebelum dan sesudah penerapan model kuantitatif audit pendokumentasian pada nilai $\mathrm{p}<0.05$

Adanya perbedaan yang signifikan nilai rata-rata kelengkapan seluruh komponen sebelum dan sesudah penerapan model kuantitatif audit pendokumentasian mencerminkan bahwa pelaksanaan model ini lebih baik atinging model konvensional.

Dapat dikatakan bahwa:

a. Model Kuantitatif ini dapat melacak tiap rekam medis yang diaudit. Adanya data yang lengkap dan terperinci serta dapat dirujuk maka kelengkapan rekam medis dengan model Kuantitatif ini memungkinkan dilakukan koreksi terhadap bagian dari rekam medis yang masih dapat dilengkapi.

b. Model kuantitatif komponen yang ada terstruktur sehingga para mahasiswa yang diberi pelatihan Model Kuantitatif Audit Pendokumentasian RM dapat dengan pasti dan jelas dalam mengukur subkomponen dari komponen-komponen kelengkapan RM ini.

c. Model kuantitatif merupakan model yang sesuai diterapkan bagi mahasiswa sehingga pada saatnya didunia kerja dapat menerapkannya dan hal ini akan meningkatkan mutu RM itu sendiri sehingga

Bila dibandingkan dengan penelitian yang relevan; Sani (2016) dalam penelitian "Perbedaan Hasil Belajar Siswa Menggunakan Model Pembelajaran Latihan Inkuiri Dengan Pembelajaran Konvensional Pada Mata Pelajaran Fisika" disimpulkan bahwa ada perbedaan yang signifikan hasil belajar siswa dalam mata pelajaran fisika yang diajar model inkuiri dengan pembelajaran konvensional.

Sejalan dengan Sani, hasil pengukuran dengan model konvensional lebih rendah atinging model Kuantitatif. Juga pada model kuantitatif dapat dijelaskan subkomponen yang perlu diperbaiki dan dapat dikoreksi dalam meningkatkan mutu kelengkapan rekam medis. Secara retrospektif subkomponen dari identifikasi pasien dan autentikasi penulis yang belum tertulis masih dapat ditambahkan karena dilakukan dengan merujuk kembali pada RM yang terkait.

Dengan dilakukannya audit model kuantitatif dilakukan intervensi dengan melakukan tindak lanjut terhadap bagian yang belum lengkap dan masih mungkin dilengkapi oleh pemberi pelayanan seperti penulisan identifikasi pasien, kelengkapan catatan saat pulang, nama dan tandatangan penulis sedangkan kurangnya pencatatan tidak boleh ditambah atau dikurangi dan tidak dapat diintervensi. Demikian juga dan teknik pencatatan. Kedua komponen ini digunakan sebagai informasi audit untuk perbaikan pada masa yang akan ating.

Dapat dibandingkan sebagai berikut :

1. Kelengkapan identifikasi pasien dapat ditingkatkan dari $99.2 \%$ menjadi $100 \%$. Identifikasi pasien yang belum terisi masih dapat dilengkapi sehingga pada model kuantitatif dapat ditingkan menjadi $100 \%$

2. Kelengkapan laporan yang penting 90,67\% menjadi $94 \%$. Catatan saat pulang/resume medis dapat dilengkapi sesudah proses perawatan dan pengobatan karena dibuat saat pasien akan pulang atau sudah pulang. Sehingga persentase kelengkapan Laporan penting dapat ditingkatkan. Namun demikian ada bagian rekam medis yang tidak bisa dikoreksi atau dilengkapi oleh karena kelalaian penulis tidak mencatat saat pemeriksaan pada perawatan dan pengobatan seperti Pengkajian awal yang dilakukan perawat 
dan dokter saat pasien baru masuk rawat atau tidak adanya Informed Consent (Surat Persetujuan Tindakan Kedokteran) yang sangat penting dan wajib adanya persetujuan pasien/ keluarganya sebelum dilakukan tindakan. Hal ini akan menjadikan rekam medis tersebut menjadi "Delinquent Medical Record".

Hal ini sejalan dengan ketentuan Pedoman Penyelenggaraan Rekam Medis (2006) bahwa rekam medis yang tidak lengkap masih dapat dilengkapi sesudah pasien pulang.

3. Kelengkapan autentikasi penulis baik dokter maupun perawat juga dapat ditingkatkan dari $85.7 \%$ menjadi $100 \%$.

Untuk meningkatkan teknik pencatatan yang baik dapat dilakukan dengan sosialisasi kepada para pemberi pelayanan untuk lebih baik agar pada pelaksanaan pendokumentasian rekam medis pada masa yang akan datang dapat dibaca dengan jelas dan koreksi kesalahan yang dilakukan sesuai dengan ketentuan yang berlaku.

\section{SIMPULAN DAN SARAN}

\section{Simpulan}

1. Rata-rata kelengkapan Rekam Medis berdasarkan model konvensional audit pendokumentasian RM sebesar $=79.98 \%$. Pencapaian kelengkapan pengisian identitas pasien dan laporan yang penting masuk dalam kategori "baik" sedangkan komponen Autentikasi penulis dan Teknik pencatatan masih dalam kategori "cukup" .

2. Rata-rata kelengkapan Rekam Medis berdasarkan model Kuantitatif audit Pendokumentasian RM sebesar $89.8 \%$. Pencapaian kelengkapan pengisian rekam medis pada katagori "baik" untuk semua komponen.

3. Adanya perbedaan yang signifikan nilai ratarata kelengkapan seluruh komponen sebelum dan sesudah penerapan model kuantitatif audit kelengkapan pendokumentasian RM mencerminkan bahwa pelaksanaan model ini lebih baik dibanding model konvensional.

a. Model Kuantitatif ini terstruktur. Dapat melacak tiap rekam medis yang diaudit, sehingga diperoleh data yang lengkap dan terperinci

b. Dapat dilakukan koreksi terhadap bagian dari rekam medis yang masih memungkinkan untuk dilengkapi.

c. Mahasiswa yang diberi pelatihan Model Kuantitatif Audit Pendokumentasian
RM dapat dengan pasti dan jelas dalam mengukur kelengkapan subkomponen dari komponen-komponen kelengkapan RM ini.

d. Mahasiswa dapat menerapkan model kuantitatif ini dengan baik dan mengerti

\section{Saran}

1. Dengan dilakukannya audit model kuantitatif perlu dilakukan intervensi setelah audit dengan melakukan tindak lanjut terhadap bagian yang belum lengkap dan masih mungkin dilengkapi oleh pemberi pelayanan seperti penulisan identifikasi pasien, kelengkapan catatan saat pulang, nama dan tandatangan penulis sedangkan kurangnya pencatatan tidak boleh ditambah atau dikurangi dan tidak dapat diintervensi. Demikian juga dan teknik pencatatan. Kedua komponen ini digunakan sebagai informasi audit untuk perbaikan pada masa yang akan datang.

2. Untuk meningkatkan teknik pencatatan yang baik dapat dilakukan dengan sosialisasi kepada para pemberi pelayanan untuk lebih baik agar pada pelaksanaan pendokumentasian rekam medis pada masa yang akan datang dapat dibaca dengan jelas dan koreksi kesalahan yang dilakukan sesuai dengan ketentuan yang berlaku.

3. Pembelajaran model audit kuantitatif perlu ditingkatkan bagi mahasiswa agar pelaksanaan audit RM dapat terstruktur dan mutu kelengkapan RM dapat ditingkatkan sehingga dapat digunakan untuk berbagai keperluan.

\section{DAFTAR PUSTAKA}

Depkes RI. 2008. Standar Pelayanan Minimal. Dirjen Yanmed Depkes RI, Jakarta.

Hatta, Gemala R.2008. Pedoman Manajemen Informasi Kesehatan, UI Press, Jakarta

KARS, 2017. Standar Nasional Akreditasi Rumah Sakit, Komisi Akreditasi RS. Jakarta.

Kemkes RI. 2006. Pedoman Penyelenggaraan Rekam Medis. Menkes, Jakarta

Kemenkes RI. 2008. Permenkes no.269/MENKES/ PER/III/ 2008, Tentang Rekam Medis. Menkes, Jakarta. 
Kemkes RI. 2011. Standar Akreditasi Rumah Sakit,(1). Menkes, Jakarta

Lima, Ayu. 2012. Tinjauan Kelengkapan Rekam Medis Rawat Inap Pada Pembuatan Resume Medis Di Rumah Sakit Siaga Raya Jakarta. Repositori UEU, Jakarta.

LaTour, Kathleen M.et al. 2010. Health Information Management (3). AHIMA. Chicago- Illinois

Ruthann Russo.2013. Documentation for MR. AHIMA. Chicago- Illinois.

Sabri, Lukito dan Hastono, Sutanto Priyo. (2014), Statistik Kesehatan (7). PT Raja Grafindo Persada, Jakarta.

Sani, RA., et.al. 2011. Perbedaan Hasil Belajar Siswa Menggunakan Model Pembelajaran Latihan Inkuiri Dengan Pembelajaran Konvensional Pada Mata Pelajaran Fisika. Jurnal Penelitian Inovasi Pembelajaran Fisika. 3(2) :25-30
Sayono, Ripto .2011.Tinjauan Kelengkapan Rekam Medis Rawat Inap Penyakit Dalam di RSUD Pasar Rebo. Repositori UEU. Jakarta.

Sekretariat Negara. 2004. UU RI No.29. Praktek Kedokteran.

Sugiyono. 2007. Metode Penelitian Kuantitatif, Kualitatif dan R\&D. Alfabeta. Bandung

Trisianawati, E., et.al. 2016. Model Pembelajaran Kooperatif Tipe Jigsaw Terhadap Hasil Belajar Siswa Pada Materi Vektor Di Kelas X Sma Negeri 1 Sanggau Ledo". Jurnal Penelitian Fisika dan Aplikasinya. JPFA. 6 (2): 51-60

Widjaja, L.2013. Pengaruh Peresepan Elektronik Terhadap Mutu Layanan Farmasi Di Rumah Sakit "X" Jakarta Barat, Jurnal INOHIM 1(2): $52-56$ 